\title{
Occupational hydrocarbon exposure and nephrotoxicity: a cohort study and literature review
}

\author{
P Pai, A Stevenson, H Mason, G M Bell
}

\section{Summary}

Hydrocarbon exposure has been shown to play an important role in the development of renal dysfunction in several occupational settings. In this study, renal screening was performed in a group of paint sprayers with exposure to hydrocarbonbased paints, recruited from a car manufacturing plant where personal protective equipment was widely used. The hydrocarbon exposure scores and various markers of renal injury were compared between these subjects and a group of paint sprayers from a previous study who did not use personal protective equipment regularly. Cumulative hydrocarbon exposure scores were calculated from a validated questionnaire. Serum creatinine, urinary total protein, albumin, transferrin, retinol-binding protein, and $\boldsymbol{N}$-acetylglucosaminidase were evaluated. Both groups experienced heavy hydrocarbon exposure but sprayers who regularly used personal protective equipment had significantly reduced exposure scores due to improved skin and respiratory protection. A significant number of sprayers from both groups had elevated levels of serum creatinine. Interestingly, urinary $\boldsymbol{N}$-acetylglucosaminidase activity, a marker of proximal tubular damage, was abnormal in a significant proportion of sprayers in the unprotected group but normal in those with improved protection.

Our results are in keeping with the hypothesis that hydrocarbon exposure through paint spraying may result in

Regional Renal Unit, Royal Liverpool University Hospital, Liverpool, UK P Pai

G M Bell

\section{Health and Safety}

Laboratory, Sheffield, UK

A Stevenson

H Mason

Correspondence to Dr Pearl Pai, Renal Unit, Sunderland Royal Hospital, Kayll Road, Sunderland SR4 7TP, UK

Accepted 20 August 1997 active proximal tubular damage which may be reduced by improvement of protection at the worksite. However, renal impairment independent of tubular injury may result from chronic paint exposure, even with improved protection.

Keywords: hydrocarbon; nephrotoxicity; $N$-acetyl glucosaminidase

Many hydrocarbons have been shown to be renal tubulotoxins but epidemiological casecontrol studies have suggested a causal link between the development of glomerulonephritis and chronic hydrocarbon exposure. Several

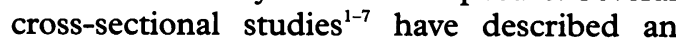

association between glomerular and renal tubular disturbances and worksite hydrocarbon exposure. However, the pathomechanism of hydrocarbon-induced nephropathy remains unclear. In addition, it is not known whether minimising exposure can reduce or reverse renal injuries.

In order to investigate further the pathomechanism of hydrocarbon induced nephropathy, we have quantitated the hydrocarbon exposure score in a group of car sprayers (group 2) using a detailed and validated occupational questionnaire, ${ }^{8}$ with a detailed assessment of their working environment and protection and compared the results with a comparable group of historic controls (group 1) who less frequently experienced respiratory and dermal protection. ${ }^{9}$ Early markers of renal dysfunction such as urinary total protein, albumin, transferrin, retinol-binding protein, $N$-acetylglucosaminidase, and serum creatinine were also compared between the two groups.

\section{Materials and methods}

The two groups of car sprayers worked in two different major car manufacturing plants in the Northwest of England. Group 1 (car plant 1) comprised 112 healthy paint sprayers and group 2 (car plant 2) comprised 47 healthy paint sprayers. A group of 92 press shop workers, who also worked at car plant 1 and who had minimal background hydrocarbon exposure was used as internal controls (group 3). All workers who were eligible consented to the study which was approved by the local ethical committee. Subjects with prior significant lead or heavy metal exposure and those with hypertension, diabetes mellitus, or renal disease were excluded. Subjects who were currently taking medication, including analgesics, or who had a past history of regular analgesic consumption were also excluded from the study.

All subjects underwent a brief medical examination. Blood pressure, height, weight and urinalysis results were recorded and all sprayers were assessed for cumulative hydrocarbon exposure score using a validated questionnaire. $^{89}$

In order to avoid any recall bias, none of the subjects had any prior knowledge of the content of the questionnaire. The questionnaire comprised four parts. Part 1 enquired about the types of activities (occupational and hobbies) 
Table 1 Characteristic of study population, parameters as mean +/- SEM

\begin{tabular}{|c|c|c|c|}
\hline & $\begin{array}{l}\text { Group } 1 \text { sprayers } \\
(n=112)\end{array}$ & $\begin{array}{l}\text { Group } 2 \text { sprayers } \\
(n=47)\end{array}$ & $\begin{array}{l}\text { Group } 3 \text { controls } \\
(n=92)\end{array}$ \\
\hline Age (years) & $45+/-0.57$ & $43+/-1.43$ & $42+/-0.73$ \\
\hline Length of employment (years) & $21(13-25)$ & $17(5-32)$ & $19(11-28)$ \\
\hline $\begin{array}{l}\text { Hydrocarbon exposure score } \\
\text { mean (range) }\end{array}$ & $\begin{array}{l}78000 \\
(15500-156000)\end{array}$ & $\begin{array}{l}57000 \\
(16200-125000)\end{array}$ & $\begin{array}{l}19000 \\
(7500-29700)\end{array}$ \\
\hline Height (m) & $1.74+/-0.006$ & $1.73+/-0.01$ & $1.75+/-1.14$ \\
\hline Weight (kg) & $79.3+/-1.12$ & $80.3+/-1.65$ & $79.1+/-1.14$ \\
\hline \multicolumn{4}{|l|}{ Blood pressure $(\mathrm{mmHg})$} \\
\hline $\begin{array}{l}\text { systolic } \\
\text { diastolic }\end{array}$ & $\begin{array}{l}129+/-1.01 \\
80+/-0.71\end{array}$ & $\begin{array}{l}132+/-2.26 \\
83+/-1.02\end{array}$ & $\begin{array}{l}128+/-1.12 \\
79+/-0.84\end{array}$ \\
\hline
\end{tabular}

which result in various types of hydrocarbon exposure in materials such as paints, varnishing agents, paint strippers, glue, carpet or floor cleaning agents, grease, degreasing agents, petroleum products, detergents, polystyrene, printing inks, hair sprays, insecticides, and anaesthetic agents. The duration of exposure to each type of hydrocarbon, if any, was recorded as hours per days, weeks per year and the number of years of exposure. The intensity of hydrocarbon exposure was derived from the prevailing working conditions, such as the use of protective equipment, and indoor or outdoor exposure according to a validated assessment score. ${ }^{8}$ Part 2 of the questionnaire enquired about the smoking habits of each subject, including the quantity of tobacco consumed. Part 3 enquired about the drinking habits, and the units of alcohol consumed per week. Part 4 enquired about analgesic intake.

Hydrocarbon exposure scores were estimated as the products of the appropriate intensity factor and the total number of hours of exposure to the individual classes of hydrocarbon.

For the purpose of this study, an intensity factor of two (non-protective occupational painting) has been used for the calculation of exposure score for both groups of paint sprayers. However, for group 2 sprayers, the intensity factor was adjusted to 1 for the period 1991 until the time of study in 1995, during which time compulsory use of personal protective equipment was in force.

Each subject provided a blood sample and a timed $(3-4 \mathrm{~h})$ urine collection on the morning of the interview. Serum and urinary creatinine was measured using an automated method based on that described by Jaffe in 1886. Urine parameters were measured and corrected per mmol creatinine excretion. Total urinary protein was measured using an automated version of the Coomassie dye binding assay. Urinary albumin was determined using an immunoturbidometric assay. Urinary $N$-acetylglucosaminidase was determined by an enzyme assay using $p$-nitrophenol-linked substrate. Urinary transferrin was measured by a latex-enhanced, homogenous competitive immunoassay. Retinol-binding protein was measured by an enzyme-linked immunosorbent technique. All assays were subject to internal quality assurance schemes.

The findings of this study was compared to those of a previous study of 112 car sprayers (group 1) who were comparable in age and duration of employment and drawn from the same residential area. A group of press shop workers (group 3) were used as internal controls.

The reference ranges of all of the parameters were derived from laboratory reference statistics. The prevalence of abnormal results was compared within the three groups using $\chi^{2}$ tests. Student's $t$-test was used for the comparative analysis of the study population's characteristics such as age, duration of employment, blood pressure and physical characteristics. The hydrocarbon exposure scores, tobacco, alcohol and analgesic data between the three groups were compared using the MannWhitney U test.

\section{Results}

The main constituents of paint as recorded from the Materials Health, Safety \& Environment data sheet, were acetone, toluene, 2-ethoxyethyl acetate, methylethyl-ketone, ethyl glycol-diacetate and xylene before 1991, and xylene, butanol, 2-butoxyethyl acetate, isobutanol, $n$-butyl acetate, propylbenzene, mesitylene, and $\mathrm{C} 9 / \mathrm{C} 10$ aromatic hydrocarbon from 1991 onwards. Sprayers were required to clean their spray gun regularly with cleaning solvents, the main constituents of which were methoxy propanol, methoxy propyl acetate, solvent naphtha light, and dibasic ester.

The subjects in both sprayer groups were comparable with respect to age, height, weight, residential areas, the duration of employment, blood pressure, smoking status, and alcohol consumption (table 1). Despite the greater range of duration of employment in group 2 sprayers, the $95 \%$ confidence interval for the mean was 14.5-19.1, so most sprayers had similar overall duration of paint exposure.

Both groups of sprayers had significant exposure to occupational paints. However, the exposure score of group 2 was significantly lower than that of group $1(p=0.0002)$ due to their improved worksite protection (widespread use of heavy duty overalls, thick gloves, barrier cream, and most importantly, air-fed mask for airway and face protection) for four years prior to the study. In group 1, in many instances, air-fed masks, if provided, were infrequently worn and the protection offered by gauze masks was minimal.

One subject in group 2 had dipstick haematuria and three others had dipstick proteinuria compared to seven subjects in group 1 with dipstick haematuria and four with proteinuria. The prevalence of abnormal results in each group estimated from laboratory reference values are shown in table 2. A significant proportion of sprayers were shown to have elevated serum creatinine above $100 \mu \mathrm{mol} / \mathrm{l}$ (12/112 from group 1 and 8/47 from group 2$)$. In addition, elevated proteinuria was observed in both groups (12/112 from group 1 and 6/47 from group 2).

Urinary $N$-acetylglucosaminidase activity was abnormal in a significant proportion of sprayers in group 1 while it was not significantly different from control in those with 
Table 2 The prevalence of abnormal renal results in the three study groups compared to the upper reference values derived from laboratory reference. Data from group 1 have been previously published, ${ }^{9}$ and are reproduced here by kind permission of Oxford University Press

\begin{tabular}{|c|c|c|c|}
\hline & $\begin{array}{l}\text { Group 1 } \\
\text { sprayers } \\
(n=112)\end{array}$ & $\begin{array}{l}\text { Group } 2 \\
\text { sprayers } \\
(n=47)\end{array}$ & $\begin{array}{l}\text { Group } 3 \\
\text { controls } \\
(n=92)\end{array}$ \\
\hline Score (median) & $74000^{\star}$ & $58000^{\wedge}$ & 19000 \\
\hline Serum creatinine $(>100 \mu \mathrm{mol} / \mathrm{l})$ & $10.7 \% \star$ & $17 \%$ & $1.1 \%$ \\
\hline Urinary protein $(>13.5 \mathrm{mg} / \mathrm{mmol}$ creat $)$ & $10.7 \% \star \star$ & $12.7 \%^{\wedge}$ & $1.1 \%$ \\
\hline Urinary albumin ( $>3.5 \mathrm{mg} / \mathrm{mmol}$ creat) & $1.8 \%$ & $4.3 \%$ & $2.1 \%$ \\
\hline Urinary $N$-acetylglucosaminidase & & & \\
\hline (>1.25 IU/mmol creat) & 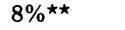 & $2.1 \%$ & $1.1 \%$ \\
\hline $\begin{array}{l}\text { Urinary transferrin ( }>0.36 \mathrm{mg} / \mathrm{mmol} \text { creat }) \\
\text { Urinary retinol-binding protein }\end{array}$ & $3.6 \%$ & $4.3 \%$ & 0 \\
\hline (>22 $\mu \mathrm{g} / \mathrm{mmol}$ creat) & $1.8 \%$ & 0 & 0 \\
\hline
\end{tabular}

^Group 1 vs Group 3; ‘Group 2 vs Group 3

$\mathrm{p}<0.01^{\star}, \mathrm{p}<0.05^{\star \star}, \mathrm{p}=0.001^{\wedge}, \mathrm{p}<0.01^{\wedge}$ glycosaminoglycan excretion and fractional albumin clearance in the exposed groups compared to controls. More recently, a collaborative European study ${ }^{7}$ has assessed the renal effects of occupational exposure to perchloroethylene in dry cleaners using large battery of markers of renal damage, and indicated changes consistent with diffuse abnormalities along the nephron.

It is interesting to observe the pattern of renal abnormalities in this study; a significant proportion of sprayers from both groups have elevated serum creatinine levels compared to controls, suggesting that renal impairment may result from chronic paint exposure.

The two groups of sprayers in our study were comparable in age and duration of employment, both of which might influence the renal parameters. However, group 2 sprayers had much improved protection at their worksite following compulsory introduction of air-fed masks with hand barrier cream and lined gloves for four years prior to this study.

Because sprayers of both groups used to have constant direct contact with paint products through inhalation and dermal absorption, an intensity factor of 2 had been used for the calculation of exposure score. However, as the group 2 sprayers had been using compulsory personal protective equipment for four years prior to this study, the intensity factor was adjusted to 1 during this later period of time for group 2.

Elevated urinary albumin and transferrin are usually indicative of early changes in the polyanionic glomerular basement membrane barrier or altered tubular handling of these proteins. ${ }^{13}$ Only small rises in urinary albumin and transferrin were observed in both groups of sprayers. The elevated proteinuria in the present study probably represents other tubular enzymuria, lysozymes or renal tubular antigens not measured in this study. Indeed, a significant proportion of sprayers from group 1 were known to have elevated urinary leucine aminopeptidase and $\gamma$-glutamyl transferase (brush border enzymes). ${ }^{9}$

Urinary retinol-binding protein is regarded as a marker of proximal tubular function of protein reabsorption whereas urinary $N$-acetylglucosaminidase is known to be distributed more widely along the nephron and is released as a result of tubular damage. No changes in urinary retinol-binding protein were detectable in the two groups of sprayers compared to laboratory reference. Urinary $N$-acetylglucosaminidase was elevated in a significant proportion of sprayers from group 1 but only one sprayer from group 2 had elevated excretion of this enzyme. Urinary $N$-acetylglucosaminidase has been shown to be a sensitive marker of active proximal tubular damage. ${ }^{14}$ Our previous study ${ }^{9}$ demonstrated an increase in urinary $\mathrm{N}$-acetylglucosaminidase in a significant proportion of sprayers, in keeping with the hypothesis that hydrocarbon-based paint is a cause of proximal tubular damage. It is likely that the reduced prevalence of abnormal urinary $N$-acetylglucosaminidase in the bon exposure based on a retrospective hydrocarbon exposure score similar to that used in our study, and demonstrated an increase in 
present study is the result of improved respiratory tract and skin protection. By way of analogy, in patients with analgesic nephropathy, elevated urinary $\mathrm{N}$-acetylglucosaminidase activities fell during remission from analgesic intake and tubulotoxicity. ${ }^{15}$ Similarly, urinary $\mathrm{N}$-acetylglucosaminidase has been shown to decline in hypertensive patients following treatment with antihypertensive therapy. ${ }^{16}$

Three hypotheses may be used to explain the renal impairment induced by hydrocarbons. It is possible that chronic renal tubular injuries lead to release of sequestered tubular antigens and subsequent immune complex formation and glomerular deposition. ${ }^{17}$ Solvents may also cause generalised membrane disturbance, either directly or through their reactive metabolites. ${ }^{18}$ It is also possible that hydrocarbons have a direct toxic effect on the glomerulus, ${ }^{18} 19$ as well as being renal tubulotoxins.

Some of the previous studies in this area can be criticised for the lack of clearly defined inclusion and exclusion criteria, and for not considering factors such as height and weight blood pressure, analgesic intake, smoking, and alcohol consumption. In this regard, serum creatinine is related to individual's muscle mass. Cigarette smoking is associated with proteinuria, ${ }^{20}$ and alcohol may affect hydrocarbon biotransformation and its renal effect. ${ }^{2122}$ Analgesic consumption can interfere with tubular function ${ }^{23}$ and cause renal impairment. ${ }^{24}$ Hypertension can cause glomerulotubular damage ${ }^{1625}$ independently. We have addressed these criticisms in the design of both sections of this study.

These data suggest that hydrocarboninduced proximal tubular injuries may be

1 Askergren A, Allgen LG, Bergstrom J. Studies on kidney function in subjects exposed to organic solvents. I. Excretion of albumin and beta-2-microglobulin in the urine. Med Scand 1981;209:479-83.

2 Askergren A. Studies on kidney function in subjects exposed to organic solvents. III. Excretion of cells in the urine. Acta Med Scand 1981;210:103-6.

3 Franchini I, Cavatorta A, Falzoi M, Lucertini S, Mutti A. Early indicators of renal damage in workers exposed to organic solvents. Int Arch Occup Environ Health 1983;52:19.

Lauwerys R, Bernard A, Viau C, Buchet JP. Kidney disorder and haematoxicity from organic solvent exposure. Scand Work Environ Health 1985;11(suppl 1):83-90.

5 Viau C, Bernard A, Lauwerys R, et al. A cross sectional survey of kidney function in oil refinery employees. $\mathrm{Am} \mathcal{F} \mathrm{Med}$ 1987;2:177-87.

6 Hotz P, Pilliod J, Berode M, Rey F, Boillat MA Glycosaminoglycans, albuminuria and hydrocarbon exposure. Nephron 1991;58:184-91.

7 Mutti A, Alinovi R, Bergamaschi E, et al. Nephropathies and exposure to perchloroethylene in dry-cleaners. Lancet 1992; 340:189-93.

8 Bell GM, Gordon ACH, Lee P, et al. Proliferative glomerulonephritis and exposure to organic solvents. Nephron 1985; 40:161-5.

9 Yaqoob M, Bell GM, Stevenson A, Mason H, Percy DF Renal impairment with chronic hydrocarbon exposure. $Q \dot{f}$ Med 1993;86:165-74

10 Lauwerys RR, Bernard A. Early detection of the nephrotoxic effects of industrial chemicals: State of the art and toxic effects of industrial chemicals: State of the

11 Yaqoob M, Bell GM. Organic solvents and renal disease. In: Holgate ST, ed. New horizons in medicine, no 6 . Oxford: Blackwell Science, 1995: pp 206-17.

12 Mutti A, Lucertini S, Falzoi M, Cavatorta A, Franchini I. Organic solvents and chronic glomerulonephritis: a cross sectional study with negative findings for aliphatic and alicyclic C5-C7 hydrocarbons. F Appl Toxicol 1981;1:224-6. reduced by maximising protection at worksites. However, a significant proportion of sprayers from both groups had impaired renal function as evident from an elevated levels of serum creatinine. This finding suggests that while recent changes in personal environmental protection may be beneficial, longer term renal problems may remain in a proportion of people.

It appeared that hydrocarbons may be responsible for a diverse effect on the glomeruli and renal tubules in susceptible individuals. Renal impairment following chronic hydrocarbon exposure may be irreversible or slow to improve, unlike tubular injuries, as reflected in urinary $N$-acetylglucosaminidase excretion, which perhaps resolve more rapidly when solvent exposure is reduced by increasing protection.

Although it is still uncertain as to the long-term renal effects of hydrocarbons, various case-control studies have demonstrated an increased prior hydrocarbon exposure in subjects with chronic glomerulonephritis. ${ }^{8}$ The constituents of paint have changed considerably over the years and it is difficult to incriminate specific 'hydrocarbons' in the causation of renal toxicity. The subtle abnormalities demonstrated in this study may act as adverse factors for potentially progressive renal diseases. Follow-up studies are necessary to assess the prognostic value of early renal changes detected in workers chronically exposed to organic solvents.

We are indebted to the men, management and medical staff of the two car plants; without their help and encouragement, these studies would not have been possible.

This project was funded jointly by Mersey Kidney Research and the Health \& Safety Executive.

13 Cheung CK, Cockram CS, Yeung VTF, Swaminathan R Urinary excretion of transferrin by non-insulin dependen diabetics: a marker for early complications. Clin Chem 1989, 35:1672-4.

14 Price RG. Urinary enzymes, nephrotoxicity and renal disease. Toxicology 1982;23:99-134.

15 Tucker SM, Boyd PJR, Thompson AE, Price RG. Automated assay of $\mathrm{N}$-acetyl-beta-glucosaminidase in normal and pathological urine. Clin Chim Acta 1975;62.333-9.

16 Alderman MH, Melcher L, Drayer D, Reidenberg MM. Increased excretion of urinary N-acetyl- $\beta$-DIncreased excretion of urinary N-acetyl- $\beta$-Dwith antihypertensive therapy. $N$ Engl f Med 1983;309. 1213-7.

17 Glassock RJ, Edgington TS, Watson JI, Dixon FJ Autologous immune complex nephritis induced with renal tubular antigen. $\mathcal{F} \operatorname{Exp}$ Med 1968;127:573-87.

18 Zimmermann SW, Norbach DH. Nephrotoxic effects of long-term carbon tetrachloride administrations in rats. Arch Pathol Lab Med 1980;104:94-9.

19 Bradfield JWB, Cattell V, Smith J. The mesangial cell in glomerulonephritis. II. Mesangial proliferation caused by Habu snake venom in the rat. Lab Invest 1977;36:487-92.

20 Dales L, Feridman G, Sieglaulb AB, Geltzer C, Ury H Cigarette smoking habits and urine characterisitics. Nephron 1978;20:163-7.

21 Riihimaki V, Savolainen K, Pfaddli P, Pekari K, Sippel HW, Laine A. Metabolic interaction between $\mathrm{m}$-xylene and ethanol. Arch Toxicol 1982;49:253-6.

22 Elovaara E, Collan, Pfaffli P, Vainio $H$. The combined toxicity of technical grade xylene and ethanol in the rat. Xenobiotica 1980;10:435-45.

23 Hordon LD, Bird HA, Cooper EH. Renal tubular dysfunction in rheumatic diseases. Br $\mathcal{F}$ Rheumatol 1991;30:115-8.

4 Sandler DP, Smith JC, Weinberg CR, et al. Analgesic use and chronic renal disease. N Engl F Med 1989;320:1238-43.

25 Bianchi S, Bigazzi R, Baldari G ied albuminuria in patients with essential hypertension. $A m$. Hypertens 1991;4:291-6. 